\title{
Immobilization of cauliflower myrosinase on agar agar matrix and its application with various effectors
}

\author{
Ajeet Kumar Rai ${ }^{1,2}$, Om Prakash ${ }^{1}$, Jagdish Singh ${ }^{2}$, Prabhakar Mohan Singh ${ }^{2}$ \\ ${ }^{1}$ Department of Biochemistry, Faculty of Science, Banaras Hindu University, Varanasi-221005, U.P., India \\ ${ }^{2}$ Indian Institute of Vegetable Research, Post bag No.01, Post office- Jakhini, Shahanshahpur, Varanasi-221305, U.P., India
}

\section{Email address:}

ajeetiivr@gmail.com(A.K. Rai)

\section{To cite this article:}

Ajeet Kumar Rai, Om Prakash, Jagdish Singh, Prabhakar Mohan Singh. Immobilization of Cauliflower Myrosinase on Agar Agar Matrix and its Application with Various Effectors. Advances in Biochemistry. Vol. 1, No. 3, 2013, pp. 51-56. doi: 10.11648/j.ab.20130103.12

\begin{abstract}
The purified and thermo stable myrosinase from cauliflower seedlings was immobilized by 3.5\% agar agar matrix and immobilized myrosinase chips were stored in extraction buffer. After 48 hours $30 \%$ enzyme activity was exuded into extraction media from immobilized enzyme chips. Effect of some metal ions and organic solvents on the activity of immobilized cauliflower myrosinase was studied. Amongst selective metal ions $\left(\mathrm{Sr}^{2+}, \mathrm{Sn}^{2+}\right.$ and $\left.\mathrm{Ba}^{2+}\right), \mathrm{Sr}^{2+}$ at $4 \mathrm{mM}$ concentration exhibited marked activating effect on the activity up to 3 fold. However, $\mathrm{Sn}^{2+}$ and $\mathrm{Ba}^{2+}$ increased the activity to a certain extent and then suppressed. Activation kinetics of myrosinase in presence $\mathrm{of}^{2+}{ }^{2+}$ and $\mathrm{Sr}^{2+}$ were studied between $0-20 \mathrm{~min}$. The rate of reaction was almost constant till $15 \mathrm{~min}$ and then slight deactivation was recorded at various concentrations used. On the other hand, few heavy metal ions $\left[\mathrm{Fe}^{2+}, \mathrm{Fe}^{3+}, \mathrm{Cu}^{2+}\right.$ and $\left.\mathrm{Zn}^{2+}\right]$ strongly inhibited the activity even at lower concentrations. Several nonpolar organic solvents even at comparatively higher concentrations had detectable activation effects. Further, their activity was seen with respect totime $(27 \mathrm{~min})$. However, some protic polar organic solvents exhibited inhibitory effect with immobilized myrosinase except to butanol.
\end{abstract}

Keywords: Myrosinase, Cauliflower, Immobilization, Agar Agar, Metal Ions, Organic Solvent

\section{Introduction}

In spite of the broader use of enzymes, their applications are constrained by a number of practical problems. Besides the high cost of enzyme isolation and purification, the main problem is their fragility or sensitivity to harsh environmental conditions which results in restricted operational lifetime of enzymes and difficulty in their recovery in the active form after the process for reuse [1-4].

The most successful and the commonest way to overcome these limitations is the immobilization of enzymes [2, 4].The most important advantage of immobilization is that it leads to alteration of the original properties of enzymes which has remarkably opened the way for customizing enzyme properties for their specific applications.

Since myrosinases (thioglucoside glucohydrolase, EC $3,2,3,147)$ are of great significance in present day biotechnology with applications ranging from processed food, health products, baking, textile, paper industries, etc. hence several methods have been developed for the preparation of immobilized myrosinase, each having its own advantages and disadvantages specific to the method employed. Myrosinase was purified from Sinapis alba seeds and immobilized on different low cost solid matrices such as alumina, silica etc.[5].It was also immobilized on Nylon 6.6 and was used to build up a biosensor for total glucosinolate determination [6] and a bioreactor useful to produce a number of glucosinolate derivative products [79]. Myrosinase was also immobolized on egg shell membrane [10].

Immobilized enzymes, as compared to free or soluble enzymes, offer more advantages, e.g., enhanced stability against various denaturing conditions, higher catalytic activity, easier product and enzyme recovery, rapid termination of reaction, reusability and reduced susceptibility to microbial contamination [11-14].

The main limitations in application of immobilized enzymes include high cost and low yield $[15,16]$. Thus, an efficient, easily available and inexpensive support like agar agar with good immobilization yields may be of more versatile applications.

Agar agar is a polysaccharide and is a mixture of two components: the linear polysaccharide agarose and a 
heterogeneous mixture of smaller molecules called agaropectin. Its chemical structure gives agar agar the capacity to form very strong gels even at low concentrations. Not only being an excellent matrix, agar agar has a high porosity which leads to high capacity for protein entrapment. Additional advantages of using agar agar as a matrix are hydrophilic character, ease of derivatization, absence of charged groups which helps in preventing non-specific adsorption of substrate and products, and also commercial availability. In addition, the melting temperature of agar agar $\left(85^{\circ} \mathrm{C}\right)$ and solidifying temperature $32-40^{\circ} \mathrm{C}$ is another significant factor which favours its applicability. This has a strong gelling ability. It is acid stable and shows no protein reactivity. Moreover, the cost of this material is also low as compared with other materials commonly used for immobilization.

Therefore, this work was devoted to the immobilization of cauliflower myrosinase on agar agar and to make a suitable study of different heavy metal ions and organic solvent on immobilized enzyme.

\section{Materials and Methods}

Cauliflower seed was arranged from Seed Technology section of Indian Institute of Vegetable Research (IIVR) Varanasi. BSA and sinigrin monohydrate were obtained from Sigma Chemical Co. USA. Potassium dihydrogen orthophosphate, Potassium hydroxide, Ascorbic acid, EDTA and Folin-Ciocalteu reagent were procured from Qualigens Fine Chemicals, Mumbai, India. Agar agar was obtained from Sigma Chemical Co., USA.

The percentage immobilization is calculated as the (total activity in immobilized gel/total activity of the soluble enzyme loaded) X 100 .

\subsection{Myrosinase}

Enzyme was isolated from cauliflower (Brassica oleracea var. botrytis) seedlings and was purified to electrophoretic homogeneity by Native PAGE.

\subsection{Immobilization of Myrosinase on Agar Agar}

The purified myrosinase was immobilized in agar agar. The solutions having varying concentrations of agar agar were prepared in the extraction buffer (Potassium phosphate buffer, $20 \mathrm{mM}, \mathrm{pH}$ 7.4) by warming them at $50^{\circ} \mathrm{C}$. After cooling down to room temperature, $1.0 \mathrm{ml}$ enzyme (containing $0.190 \mathrm{mg}$ protein $/ \mathrm{ml}$ ) was mixed with $9.0 \mathrm{ml}$ of the matrix solution (the total volume of matrix and enzyme mixture being $10 \mathrm{ml}$ ) and immediately casted on preassembled glass plates. After solidification at room temperature, agar agar gel was cut into small chips of $5 \times 5$ $\mathrm{mm}$ size and washed several times before use to remove any enzyme attached to the gel surface. These immobilized chips were stored in extraction buffer in refrigerator. The activity of these chips was assayed spectrophotometrically as described in the following section. The buffer, in which these chips were stored, was also periodically checked for the activity to assess the possible leaching of the enzyme.

\subsection{Immobilized Myrosinase Assay}

Myrosinase activity was determined by measuring the rate of decrease in absorbance at $227 \mathrm{~nm}$ resulting from the hydrolysis of sinigrin as per method [17]. Two immobilized agar agar chips (3.0-4.0 $\mu \mathrm{g}$ protein/chip) were used for enzyme assay instead of the soluble form of enzyme. Protein concentrations were determined with BSA as a standard [18]. Specific activities are expressed as units/mg of protein.

\subsection{Optimization of Agar Agar Concentration for Immobilization of Myrosinase}

In order to optimize entrapment, the concentration of agar agar was varied and the extent of immobilization was assessed.

\subsection{Storage Stability of Immobilized Enzyme in Agar Agar}

In order to explore storage stability and leaching of the enzyme from immobilized preparations, freshly prepared immobilized chips were stored in extraction buffer $(20 \mathrm{mM}$ potassium phosphate buffer, $\mathrm{pH} 7.4$ ) at $4^{\circ} \mathrm{C}$. The activities of the enzyme in chips and the storage media (for leaching) were assayed at different time intervals using standard assay protocol.

\subsection{Effect of Metal ions on Immobilized Enzyme}

It was of interest to explore the possible effects of metal ions on the immobilized myrosinase. To study this, a stock solution $(50 \mathrm{mM})$ of the desired salt of metal ions $\left(\mathrm{Fe}^{3+}\right.$, $\mathrm{Zn}^{2+}, \mathrm{Cu}^{2+}$ and $\mathrm{Fe}^{2+}$ ) was made in potassium phosphate buffer (33mM, pH 6.0) and diluted with the same buffer as required.

\subsection{Effect of Heavy Metal Ions on Immobilized Enzyme}

Effect of $\mathrm{Sn}^{2+}, \mathrm{Sr}^{2+}$ and $\mathrm{Ba}^{2+}$ ions was studied in the concentration range of $1.0-40 \mathrm{mM}$, added in the standard assay mixture and assayed the activity as described earlier.

\subsection{Effect of Non Polar Organic Solvents on Immobilized Enzyme}

It is interesting to know the behaviour of immobilized enzyme in the organic solvents. The effect of some organic solvents like toluene, benzene and chloroform on the immobilized system was studied in the concentration range of $10-50 \%(\mathrm{v} / \mathrm{v})$ added in the standard assay system.

\subsection{Effect of Protic Polar Organic Solvents on Immobilized Enzyme}

In immobilized system, the effect of some protic polar organic solvents like methanol, ethanol, propanol and 
butanol was explored in the concentration range of 10-50\% (v/v) added in the standard assay system.

\section{Results and Discussion}

\subsection{Optimization of Agar Agar Concentration for Immobilization of Myrosinase}

In order to optimize entrapment, the concentration of agar agar was varied and assessed the extent of immobilization. As it is evident from table-1, there was only about $25 \%$ immobilization in $2.0 \%(\mathrm{w} / \mathrm{v})$ agar agar and the membrane also was very fragile and susceptible to damage during handling. At a concentration of 3\%, more stable agar agar chips were obtained with immobilization of about $52 \%$. Further, a concentration of $3.5 \%$ resulted in maximum immobilization $(70 \%)$. Afterward, increase in agar agar concentration resulted in to poor immobilization and at $6 \%$, the solidification of the gel occurred even before the addition of the enzyme. Therefore, 3.5\% agar agar (w/v) was selected for further studies. In a recent study, a similar finding was reported in soybean $\alpha$-amylase where $77 \%$ entrapment of enzyme obtained with $4 \%$ agar agar [19].

Table1. Effect of varying concentration of agar agar on immobilization of myrosinase.

\begin{tabular}{cc}
\hline $\begin{array}{c}\text { Agar agar concentration }(\% \\
\text { w/v) }\end{array}$ & Immobilization \% \\
\hline 2 & 25 \\
3 & 52 \\
3.5 & 70 \\
4 & 65 \\
5 & 34 \\
6 & Got solidified before the addition of \\
& enzyme \\
CD (5\%) & 27.85 \\
\hline
\end{tabular}

$\mathrm{CD}=$ Critical Difference

\subsection{Storage Stability of Immobilized Enzyme in Agar Agar}

In order to explore storage stability and leaching of the enzyme from immobilized preparations. The activities of the enzyme in chips and the storage media (for leaching) were assayed at different time intervals using standard assay protocol. The result (Table-2) indicated that upon storage, the chips leached enzyme gradually in to the storage media. Thus on fourth day of storage, the chips retained about half of the initial activity and about half of the activity was exuded into the storage buffer.
Table2. Relative activities of myrosinase in immobilized chips and in storage buffer.

\begin{tabular}{ccc}
\hline Days & $\begin{array}{c}\text { \% Relative activity in } \\
\text { immobilized chips }\end{array}$ & $\begin{array}{c}\text { \% Relative activity } \\
\text { in chip storage } \\
\text { buffer }\end{array}$ \\
\hline 0 & 100 & - \\
1 & 79 & 21 \\
2 & 70 & 30 \\
3 & 54 & 46 \\
4 & 51 & 49 \\
5 & 48 & 52 \\
CD (5\%) & 21.13 & 21.13 \\
\hline
\end{tabular}

The observations are suggestive of the fact that agar agar immobilized myrosinase can be conveniently used for 48 hrs and are not suitable of longer storage.

\subsection{Effect of Metal ions on Immobilized Enzyme}

The activity of the agar agar immobilized enzyme was determined in the presence of varying concentrations (1-10 $\mathrm{mM})$ of $\mathrm{Fe}^{3+}, \mathrm{Zn}^{2+}, \mathrm{Cu}^{2+}$ and $\mathrm{Fe}^{2+}$ added in the standard assay mixture. The results (Fig.1) revealed a concentration dependent inhibition of the activity by all the heavy metal ions studied. This observation was essentially identical to the one reported for the soluble enzyme [21].

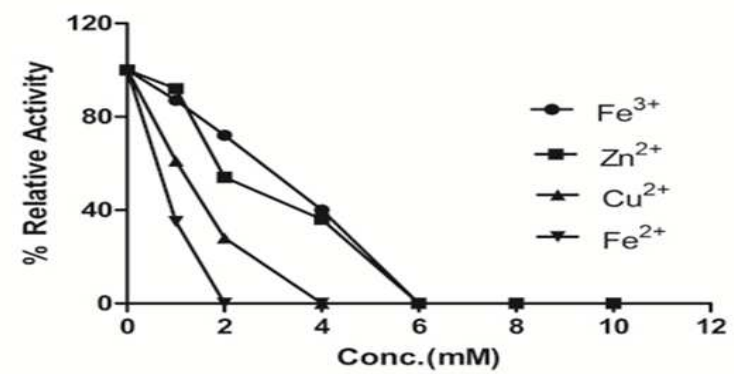

Figure 1. Effect of heavy metal ions on agar agar immobilized cauliflower myrosinase activity.

\subsection{Effect of Heavy Metal ions on Immobilized Enzyme}

These ions $\left(\mathrm{Sn}^{2+}, \mathrm{Sr}^{2+}\right.$ and $\left.\mathrm{Ba}^{2+}\right)$ at lower concentration had strong activating effects on the immobilized enzyme (Fig.2). Amongst these three ions, $\mathrm{Sr}^{2+}$ had a strongest activation effect and activity continuously increased from $0-4 \mathrm{mM}$ and maximum was recorded at $4 \mathrm{mM}$ (nearly 3 times of the control).After this activity decreased slowly and the enzyme became completely inactive at $40 \mathrm{mM}$. However, $\mathrm{Sr}^{2+}$ ions were an inhibitor of bacterial myrosinase [20]. This difference in the behaviour might be due to the structural difference in the myrosinase. Plant myrosinase had a rather large molecular weight as 
compared to the bacterial enzyme. Similarly, stannous ions had maximum activity (1.67 times of control) at $2 \mathrm{mM}$ concentration and beyond which there was a decrease in the activity, while no activity was recorded at $6 \mathrm{mM}$ onwards.

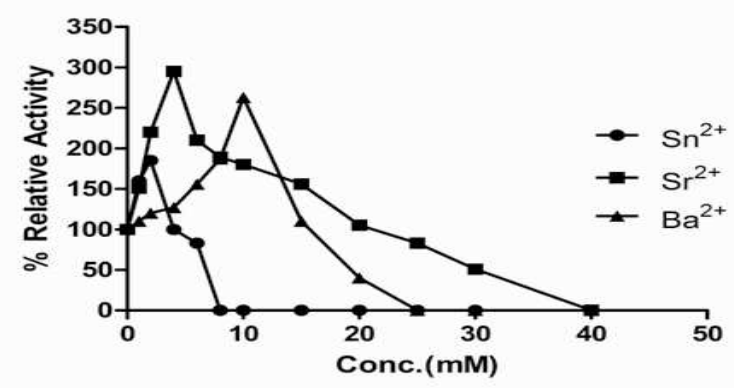

Figure 2. Effect of heavy metal ions on immobilized cauliflower myrosinase activity.

Similar observations of minor activation were also reported in bacterial myrosinase[20]. $\mathrm{Ba}^{2+}$ showed less activation amongst these metal ions and attained its maximumat $10 \mathrm{mM}$.Above results suggest that heavy metal ions are excellent activators of the immobilized enzyme at lower concentrations, with soluble enzyme showing a similar trend with lower activation effect [21].

\subsection{Time-Course of Effect of $\mathrm{Sr}^{2+}$ on the Activity of the Myrosinase}

As described earlier (Fig.2), $\mathrm{Sr}^{2+}$ at $4.00 \mathrm{mM}$ had maximum activating effect of immobilized myrosinase. In order to explore the rate of activation over time, three concentrations viz., 1, 2 and $4 \mathrm{mM}$, were selected and effect of these were studied for 20 min. Fig.3 indicated that at $4 \mathrm{mM}$ concentration of $\mathrm{Sr}^{2+}$, the rate of reaction was higher than its lower concentrations. Nearly till $15 \mathrm{~min}$ the trend of reaction was constant after which a little decrease in the activity was detected (remains $80 \%$ of maximum) till 20 $\min$.

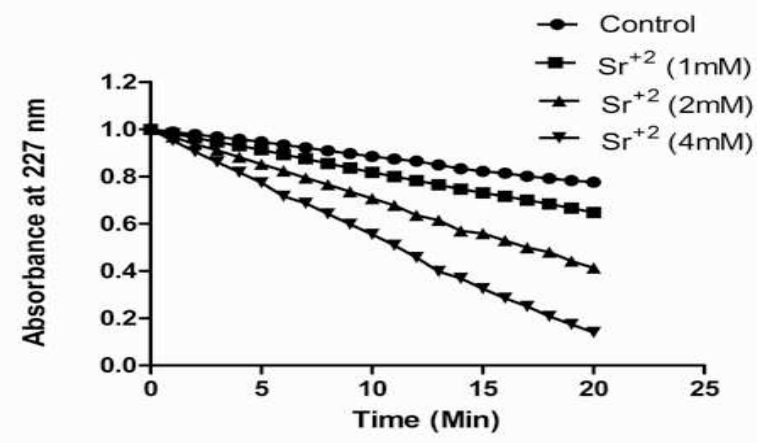

Figure 3. Time-dependent hydrolysis of sinigrin by agar agar immobilized cauliflower myrosinase with specific concentration of $\mathrm{Sr} 2+$.

\subsection{Time-Course of Myrosinase Action in Presence of $\mathrm{Sn}^{2+}$}

As has been observed earlier in Fig.2, $\mathrm{Sn}^{2+}$ exhibited activation of myrosinase activity in the concentration range of 1-6 mM. Considering this, a time-course of effect of metal ion at the concentration of $1 \& 2 \mathrm{mM}$ was studied. The metal ion was added in the reaction mixture and the progress of reaction was studied for $20 \mathrm{~min}$ (Fig.4).The result revealed that rate of reaction was constant till $13 \mathrm{~min}$ and after which little decrease in the enzyme activity was seenupto $20 \mathrm{~min}$ in both the concentrations selected.

The above results suggested that heavy metal ions at suitable concentrations are probably stabilizing the enzyme such that the myrosinase continues to act on its substrate for a longer period of time, without significant decrease in the activity. In addition, a more significant increase in enzyme activity in case of agar agar immobilized chips than soluble myrosinase are indicative of greater stabilization of cauliflower myrosinase in immobilized system than the soluble one.

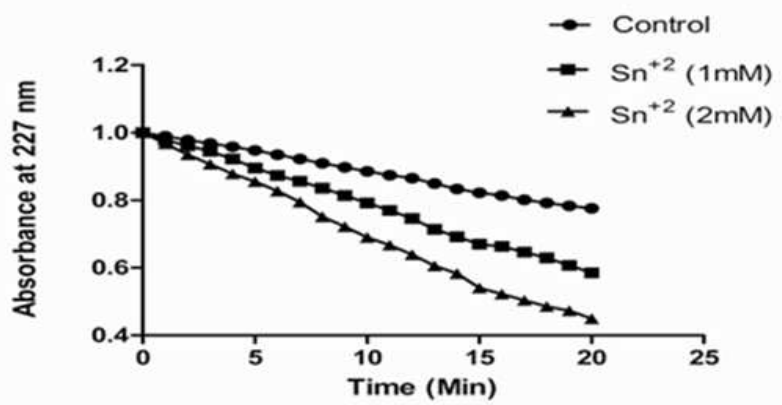

Figure 4. Time-dependent hydrolysis of sinigrin by agar agar immobilized cauliflower myrosinase with selective concentration of $\mathrm{Sn} 2+$.

\subsection{Effect of Non Polar Organic Solvents on Immobilized Enzyme}

It is interesting to know the behavior of immobilized enzyme in the organic solvents. The effect of some organic solvents like toluene, benzene and chloroform (which indicated an activation in the activity of soluble enzyme) on the immobilized system was studied in the concentration range of $10-50 \%(\mathrm{v} / \mathrm{v})$ added in the standard assay system. Fig. 5 indicated activation effect in immobilized chips over all selected concentrations. Activation pattern was toluene $>$ benzene $>$ chloroform at $50 \%(\mathrm{v} / \mathrm{v})$ concentration. The enhancement was higher in immobilized myrosinase than the soluble enzyme.

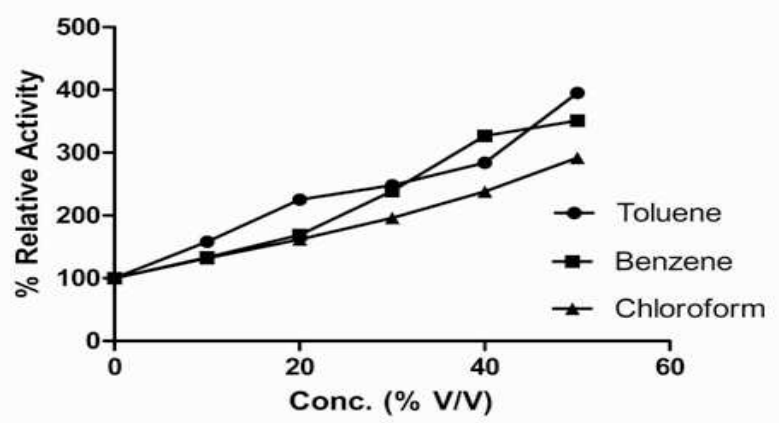


Figure 5. Effect of non polar organic solvent on agar agar immobilized cauliflower myrosinase activity.

\subsection{Time-Course of Effect of Toluene on the Activity of the Immobilized Myrosinase}

As evident earlier (Fig.5), toluene in the concentration range of $10-50 \%(\mathrm{v} / \mathrm{v})$ had activation effect on immobilized myrosinase. In order to explore the timecourse of activation, two concentrations viz., 10 and 20\% (v/v), were selected and studied for $27 \mathrm{~min}$. Fig.6 indicated that at $10 \%$ concentration of toluene, the rate of reaction was lower than $20 \%$. Time-dependent rate of reaction was recorded at these concentrations. Nearly till $19 \mathrm{~min}$ the rate of reaction was constant after which a small decrease in activity was detected up to $27 \mathrm{~min}$.

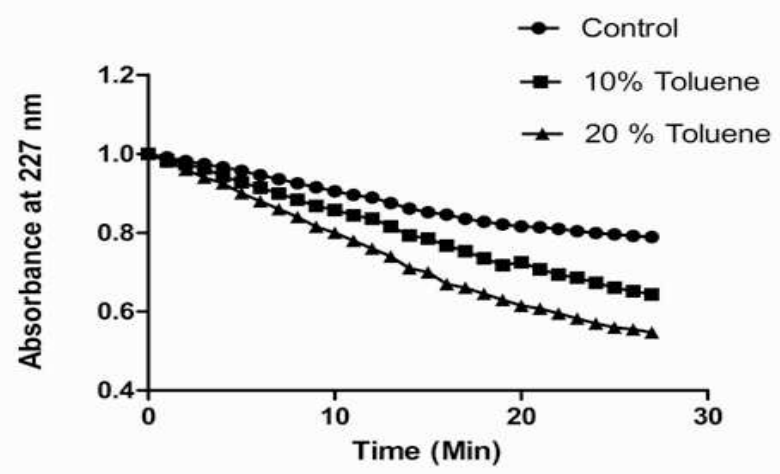

Figure 6. Time-dependent hydrolysis of sinigrin by agar agar immobilized cauliflower myrosinase.

\subsection{Time-Course of Immobilized Myrosinase Action in Presence of Chloroform}

As has been described earlier in Fig.5, chloroform also exhibited activation pattern in immobilized myrosinase. Considering this, a time-course of effect of chloroformat the concentration of $10 \& 20 \%(\mathrm{v} / \mathrm{v})$ was studied. The selected concentrations of chloroform were added in the reaction mixture and the progress of reaction was monitored up to $27 \mathrm{~min}$ (Fig.7). The result revealed that rate of reaction was constant till $16 \mathrm{~min}$ and after which little reduction in enzyme activity was noted till $27 \mathrm{~min}$ in both the concentrations selected.

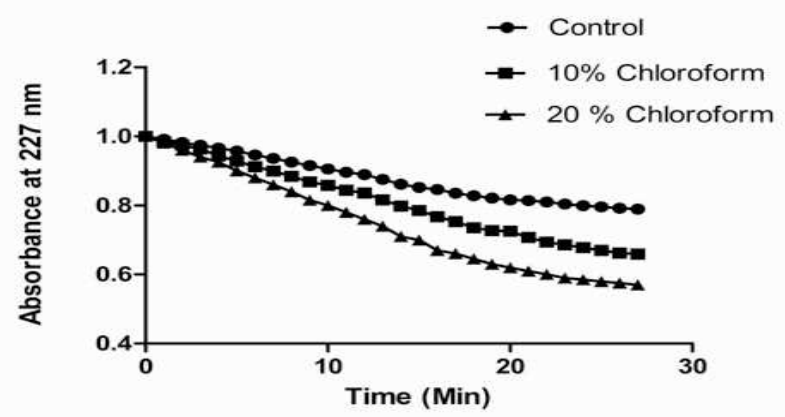

Figure 7. Time-dependent hydrolysis of sinigrin by agar agar immobilized cauliflower myrosinase.
However, the fact that immobilized myrosinase exhibited significant stability in some organic solvent is suggestive for its industrial application viz., health and processed food industry. Similar to our finding, a remarkable stability of $\alpha$ amylase (isolated from Nsterenkonia sp.) was found towards organic solvents like cyclohexane, benzene, toluene and chloroform [22]. The significant activity of soybean $\alpha$-amylase was reported in organic solventsviz., toluene, benzene and chloroform [23].

\subsection{Effect of Protic Polar Organic Solvents on Immobilized Enzyme}

In immobilized system, the effect of some protic polar organic solvents like methanol, ethanol, propanol and butanol was explored in the concentration range of $10-50 \%$ $(\mathrm{v} / \mathrm{v})$ added in the standard assay system. With the exception of butanol, these solvents have already shown inhibition effect in soluble enzyme. In this study, results (Fig.8) also indicated a similar decreasing effect in activity of immobilized chips except in the presence of butanol. Methanol, ethanol and propanol were exhibiting $\leq 50 \%$ activity at $30 \%(\mathrm{v} / \mathrm{v})$ concentrations and complete loss inactivity were seen at $50 \%(\mathrm{v} / \mathrm{v})$. The activity of myrosinase was deceased in presence of several organic solvents, like simple alcohols, but these solvents are not able to prevent reaction taking place in case of the soluble enzyme [24].

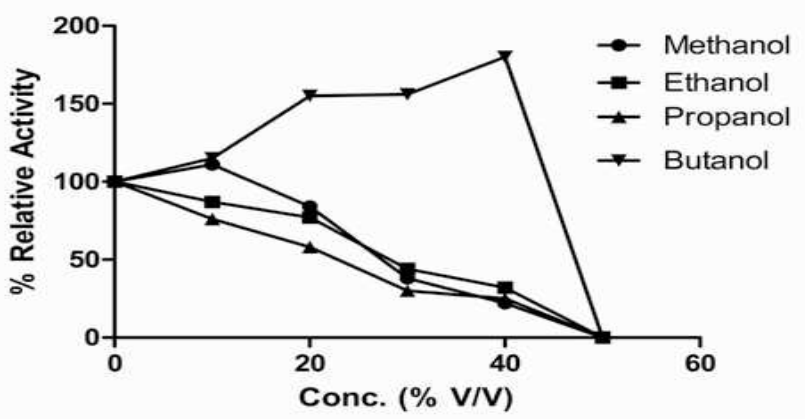

Figure 8. Effect of protic polar organic solvent on agar agar immobilized cauliflower myrosinase activity.

\section{Conclusion}

This preliminary work demonstrates that myrosinase, which is contained insignificant amounts in cauliflower seedlings and easily binds to an inexpensive solid support such as agar agar with interesting absorption and immobilization yields, with good chemical characteristics. The stability of this enzyme was better at low concentration of metal ions increasing its possibilities for application. From the technological point of view, immobilized enzymes can easily be separated from their action liquid and make laborious separation steps unnecessary. Additional benefits arise from stabilization against harsh reaction conditions which are deleterious to soluble enzyme preparations. Due to the wide variation in the properties of 
the individual enzyme species and due to the varying requirements of reaction technology for the target compounds it is advisable to exploit fully the wealth of methods and techniques of immobilization. So agar agar immobilized myrosinase is suitable for both the technical requirements and the overall business framework.

\section{References}

[1] M.F. Chaplin, and C.Bucke, The large scale use of enzymes in solution. Enzyme Technology, Cambridge University Press, 1990.

[2] R.A.Sheldon, Enzyme Immobilization: the quest for optimum performance. Advanced Synthesis and Catalysis, 349: 1289-1307, 2007.

[3] B.Krajewska, Application of chitin- and chitosan-based materials for enzyme immobilizations: a review. Enzyme and Microbial Technol., 35: 126-139, 2004.

[4] L.Q.Cao, Immobilised enzymes: science or art? Current Opinion in Chemical Biol., 9: 217-226,2005.

[5] R.Iori,O.Leoni, and S.Palmieri, Immobilization of myrosinase (Thioglucoside glucohydrolase EC 3.2.3.1) Biotechnology Letters Vol10, 8, 575-578.1988.

[6] O. Leoni,R.Iori, and S.Palmieri, Immobilization of myrosinase on membrane for determining the glucosinolate content of cruciferous material. J. Agric. Food Chem. 39, $2322-2326.1991$

[7] O.Leoni, F.Felluga, and S.Palmieri, The formation of 2hydroxybut-3-enyl cyanide from (2S)-2-hydroxybut-3-enyl glucosinolate using immobilized myrosinase. Tetrahedron Lett.49, 7967-7970.1993.

[8] O.Leoni, CMarot,P. Rollin, SPalmieri, Preparation of (5R)5-vinyloxazolidine-2-thione from natural epi-progoitrin using immobilized myrosinase. Tetrahedron Asymm.,5, $1157-1160,1994$.

[9] O.Leoni, R.Ioriand S.Palmieri, Hydrolysis of Glucosinolates Using Nylon-immobilized myrosinase to Produce Pure Bioactive Molecules. Biotechnology and Bioengineering.68 (6), 660-664, 2000.

[10] M, M,F.Choi, M.M.K Liang and A W.M Lee, biosensing method with enzyme-immobilized eggshell membranes for determination of total glucosinolates in vegetables. Enzyme and Microbial Technology 36, 91-99.2005.

[11] J.Cheng,S.M. Yu, and P.Zuo, Horseradish peroxidase immobilized on aluminium-pillared interlayered clay for the catalytic oxidation of phenolic wastewater. Water Res., 40, 283-290, 2006
[12] Y.Kulshrestha, andQ. Husain, Direct immobilization of peroxidase on DEAE cellulose from ammonium sulphate fractionated proteins of bitter gourd (Momordicacharantia). Enzyme Microb.Technol., 38, 470-477, 2006.

[13] T.Romaskevic, SBudriene, K.Pielichowski and J.Pielichowski, Application of polyurethane-based materials for immobilization of enzymes and cells: A review. Chemija, $17,74-89,2006$.

[14] K.N. Niladevi, and P.Prema, Immobilization of laccase from Streptomyces psammoticus and its application in phenol removal using packed bed reactor. World. J. Microbiol. Biotechnol.,24, 1215-1222,2008.

[15] W.Tischer, and V.Kasche, Immobilized enzymes: Crystals or carriers. TIBTECH, 17, 326-335,1999.

[16] Matto, M. and Husain, Q. (2006) Entrapment of porous and stable concanavalin A-peroxidase complex into hybrid calcium alginate-pectin gel. J. Chem. Technol. Biotechnol., 8, 1316-1323.

[17] Palmieri, S., Leoni, O.andIori, R. (1982)A study- state study of myrosinase with direct ultraviolet spectrophotometric assay. Anal.Biochem.123, 320-324.

[18] Lowry, O.H., Rosebrough, N.J., Farr, A.L. and Randall, P.J. (1951) Protein measurement with folin protein reagent. J. Biol. Chem., 193, 265-275.

[19] Prakash,O. and Jaiswal,N.(2011)Immobilization of a Thermostable -Amylase on Agaroseand Agar Matrices and its Application in Starch Stain Removal, World Applied Sciences Journal 13,3, 572-577.

[20] Tani, N., Ohtsuru, M. and Hata, T. (1974) Isolation of myrosinase producing microorganism. Agr. Biol. Chem. 38, $1617-1622$.

[21] Prakash, O., Rai,A K., Singh, J. and SinghP.M. (2013) Effect of Heavy Metal Ions and Carbohydrates on the Activityof Cauliflower (Brassica oleracea Var. botrytis) Myrosinase, journal of stress physiology \& biochemistry Vol. 9 No. 2 pp.107-117.

[22] Shafiei, M., Ziaee, A.A. and Amoozegar, M.A. (2011)Purification and characterization of an organicsolvent-tolerant halophilic $\alpha$-amylase from the moderately halophilic Nesterenkonia sp. strain F. J. Ind. Microbiol. Biotechnol.,38, 275-281.

[23] Jaiswal,N. (2011) Physico chemical characterization and molecular studies of $\alpha$-amylase from soybean seed.BHU, Varanasi.

[24] Botti, G.M., Malcom, G.T. and Nigel, P. Botting. (1995) Studies on the mechanism of myrosinase, The journal of Biological chemistry. Vol. 270, No. 35, 20530- 20535. 